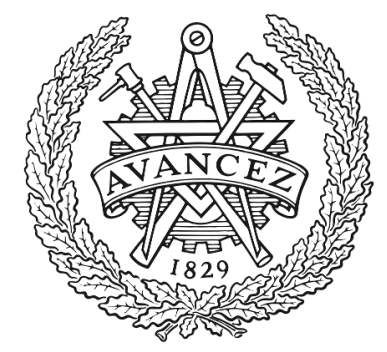

CHALMERS

UNIVERSITY OF TECHNOLOGY

\title{
Experiments and numerical analyses of blast and fragment impacts on concrete.
}

Downloaded from: https://research.chalmers.se, 2023-04-26 10:13 UTC

Citation for the original published paper (version of record):

Leppänen, J. (2005). Experiments and numerical analyses of blast and fragment impacts on concrete.. International Journal of Impact Engineering, 31(7): 843-860.

http://dx.doi.org/10.1016/j.ijimpeng.2004.04.012

N.B. When citing this work, cite the original published paper. 


\title{
Experiments and numerical analyses of blast and fragment impacts on concrete
}

\author{
Joosef Leppänen* \\ Department of Structural Engineering and Mechanics, Concrete Structures, Chalmers University of Technology, \\ SE-412 96 Göteborg, Sweden
}

Received 11 November 2003; received in revised form 20 April 2004; accepted 23 April 2004

Available online 8 June 2004

\begin{abstract}
Concrete structures are commonly used as protective structures. An important issue is how the blast wave and fragment impacts from an explosion affect the concrete. It is well known that the fragments penetrate or even perforate the structure. Moreover, spalling occurs in the impact zone and scabbing may occur on the reverse side of a wall that receives an impact. However, knowledge of how the blast wave and fragment impacts influence the material properties of concrete is quite limited. Experiments and numerical analyses were carried out to examine the extent to which the concrete, at various distances, is affected by the blast wave and fragment impacts. The fragments, which were spherical, were shot against thick concrete blocks by using the explosives octol or hexotol; the fragment velocity was approximately $1650 \mathrm{~m} / \mathrm{s}$. After the concrete blocks were shot, the depths of penetration and spalling were measured. Next, the concrete blocks were cut into halves, and the global macro-cracking could be observed. To study how the material properties of concrete were influenced, uniaxial compressive and splitting tensile tests were carried out on cylinders drilled from selected positions in the block. Furthermore, specimens from the blocks were thinground to facilitate analysing the micro-cracking with a microscope. The experiments and numerical analyses presented here showed that the damage in the concrete, from the blast wave and fragment impacts, is localized in the impact zone. The concrete below this zone, at a depth of approximately twice the depth of the maximum penetration, was hardly affected at all by the blast wave and fragment impacts. This indicates that it is possible to distinguish between the global load effects and the local damage effects that are caused by the fragment impacts. Consequently, it may be possible to separate the loads, at the design stage, from a blast wave and fragment impacts.
\end{abstract}

(C) 2004 Elsevier Ltd. All rights reserved.

Keywords: Concrete; Fragment impacts; Blast wave; Experiment; Numerical analysis

\footnotetext{
*Fax: + 46-(0)31-772-2260.

E-mail address: joosef.leppanen@sem.chalmers.se (J. Leppänen).
} 


\section{Introduction}

Since massive concrete structures withstand blast waves and fragment impacts effectively, they are often used as protective structures. According to the Swedish Shelter Regulations [1], a shelter shall withstand: the effect of a pressure wave corresponding to that produced by a $250-\mathrm{kg}$ GP bomb with $50 \%$ by weight TNT that bursts freely outside at a distance of $5.0 \mathrm{~m}$ from the outside of the shelter during free pressure release. Furthermore, according to these regulations, the shelter shall withstand the effect of fragment impacts from the same type of bomb. In design, normally, the thickness of concrete is dimensioned to withstand the fragment impacts; a static load, with a dynamic increase factor, approximates the blast load.

Experiments show that a concrete structure exposed to a combination of blast wave and fragments collapses more easily than one that is exposed only to a blast wave or fragment impacts, see Forsén and Edin [2]. The impulse density of fragment impacts is usually much lower that of a blast wave; therefore, the slightly increased impulse density observed for the combined blast wave and fragment impacts cannot explain the greater damage to the structure. It is believed that the reason for the increased damage is a combination of the spalling effect and the increased impulse density [2]. Forsén and Nordström [3] experimented with combined blast wave and fragment impacts against concrete slabs. They showed that a very good estimation of the deflection can be obtained, by taking into account that the resistance of the slab is decreased by the fragment impacts and by adding the fragment impulse density to the positive impulse density of the blast wave. The pressure-time history was rearranged to a triangular shape by using the maximum pressure from the blast wave.

Earlier experiments have dealt with the structural level: beams, walls or even entire structures were analysed [2,3] and Nordström [4]. Nevertheless, the effect of the blast wave and fragment impacts on the concrete material properties is not known in detail. The study reported in this paper aims to add to the knowledge of how the damage to concrete is affected by the blast wave and fragment impacts. The spherical fragments were shot by a detonation, with either octol or hexotol, against thick non-reinforced concrete blocks. However, in a real bomb detonation, the fragments are not spherical, and the structure is reinforced. The purpose of the simplifications in the experimental set-up was to have as few uncertain parameters as possible. With improved understanding of how the concrete material properties are influenced by the loading, other parameters can be added, for example, irregular fragments, reinforced concrete, structural elements, or even reinforced concrete structures.

The depth of penetration and cratering were measured after the concrete blocks were shot. Next, to study the damage, the blocks were cut into halves so that global macro-cracking could be observed. Uniaxial compressive and splitting tensile tests were made on drilled cylinders to study the change in strength. Furthermore, thin-ground specimens were prepared from the blocks, to facilitate analysis of micro-cracking with microscope.

Another aim was to investigate how numerical methods can simulate the experiments with the loading of combined blast wave and fragment impacts; the experimental set-up was chosen in order to have clear boundary conditions for the numerical analyses presented in this paper. In the literature several papers deal with numerical analyses of projectile penetration, as in Clegg et al. [5], Johnson and Beissel [6], Johnson et al. [7], Leppänen [8], Scheffler and Zukas [9], Zukas and Scheffler [10]. Numerical analyses of a blast wave against concrete structures were carried out by 
Johansson [11], Krauthammer [12], Krauthammer and Otani [13]. Numerical analyses of single fragment impacts were made by Ågårdh and Laine [14]; Papados [15] conducted numerical analyses of multiple fragment impacts.

In this paper numerical analyses of combined blast wave and fragment impacts were carried out, and the software used was AUTODYN [16]; this is a general-purpose program for solving a variety of non-linear problems in dynamics. The phenomena studied with this type of program can be characterized as highly time dependent with both geometric and material non-linearities. The code, which combines finite difference, finite volume, and finite element techniques, is known as a hydro-code.

\section{Experimental set-up}

The aim of the experiments was to study the damage caused by a blast wave and fragment impacts at various depths in concrete blocks. The charges and the dimensions of the concrete blocks were chosen to obtain a damage level high enough so that drilling of cylinder specimens would be possible. After casting, the concrete blocks were turned upside down, and the fragments were shot against the finer surface (at the bottom of the cast concrete). The dimensions of the blocks were $750 \times 750 \times 500 \mathrm{~mm}^{3}$, and the fragments were spherical with a radius of $4 \mathrm{~mm}$; the impact velocity was around $1650 \mathrm{~m} / \mathrm{s}$. The test set-up is shown in Fig. 1. A total of six blocks were shot with fragments. To vary the fragment area density, the charges were fired from four heights above the concrete blocks.

The charges were made by gluing bearing balls onto a convex end of a cylinder. Two similar explosives were used, octol and hexotol, both with a weight of $1.3 \mathrm{~kg}$. A total of seven charges were fired, five with octol and two with hexotol, and the height was varied between 0.6 and $1.0 \mathrm{~m}$. The fragment velocity was measured with an accelerometer and impact sensor. Although, single fragments were shot against concrete blocks, the results discussed in this paper are limited to the multi-fragment impacts. Information about the single fragment shots may be found in Leppänen [17].

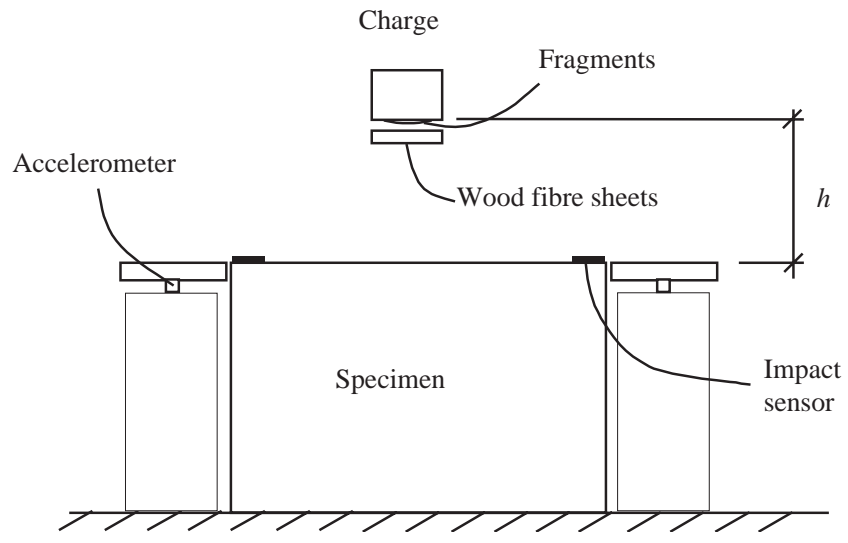

Fig. 1. Experimental test set-up. 
Table 1

Fragment impact velocities and experimental set up

\begin{tabular}{llllll}
\hline Charge nr. & Block nr. & Velocity $(\mathrm{m} / \mathrm{s})$ & Explosive material & Height $(\mathrm{m})$ & Frame \\
\hline $1^{\mathrm{a}}$ & 1 & 1450 & Octol & 1.0 & No \\
2 & 1 & 1680 & Octol & 1.0 & No \\
3 & 2 & 1660 & Octol & 0.8 & No \\
4 & 3 & 1650 & Hexotol & 0.6 & Yes \\
5 & 4 & 1650 & Octol & 0.7 & Yes \\
$6^{\mathrm{b}}$ & 5 & - & Octol & 0.7 & Yes \\
$7^{\mathrm{b}}$ & 6 & - & Hexotol & 0.6 & Yes \\
\hline
\end{tabular}

${ }^{\text {a }}$ Four wood fibre sheets with a total thickness of $51 \mathrm{~mm}$ were placed below the charge.

${ }^{\mathrm{b}}$ For charges six and seven, the velocity could not be registered; the signal that registered the velocity did not work.

The first two charges were fired against block one. For the first shot, four sheets of wood fibre were placed below the charge to reduce the velocity. The fragment impact velocity for this shot was $1450 \mathrm{~m} / \mathrm{s}$. To increase the impact velocity, the wood fibre sheets were removed for the remaining shots. For charge two, the velocity was raised to $1680 \mathrm{~m} / \mathrm{s}$. In block two (charge three) the damage at the edge was high. To facilitate drilling cylinders from the blocks (as described in Section 3.2), a steel frame was used to reduce the damage at the edges for the remaining shots. The steel frame was made of a $10 \mathrm{~mm}$ thick L-profile that covered $70 \mathrm{~mm}$ of the concrete edges. The fragment impact velocities and the experimental set-up for the seven charges fired are shown in Table 1.

\section{Experimental results}

After shooting fragments at the concrete blocks, photographs were taken; the depth of penetration, crater depth and diameter were measured. To study how the material properties were changed, drilled cylinders with dimensions of $\phi 50 \times 100 \mathrm{~mm}^{2}$ were used for uniaxial compressive and tensile tests. Furthermore, the concrete blocks were cut into halves so that the macro-cracking could be examined. To analyse micro-cracking, thin-ground sections were taken from the blocks; using a microscope, the cracks could be observed.

\subsection{Photographing the concrete blocks}

Five concrete blocks (numbered from two to six), after being struck by fragments, were photographed as shown in Fig. 2. The cracks were marked to improve the visualization. The depth of penetration varied between 30 and $50 \mathrm{~mm}$, and the crater diameter varied between 45 and $60 \mathrm{~mm}$ for the concrete blocks. To study the macro-cracking in the blocks, they were cut into halves and the crack pattern was examined, see Fig. 3 with the crack patterns marked. All five blocks had similar overall crack patterns, with clear spalling in the impact zone; the depth of the damage zone was approximately $50 \mathrm{~mm}$. At the boundaries of the blocks, a global crack pattern developed; this is caused by reflections of the stress wave generated by the impulse from the blast and fragment impacts. 

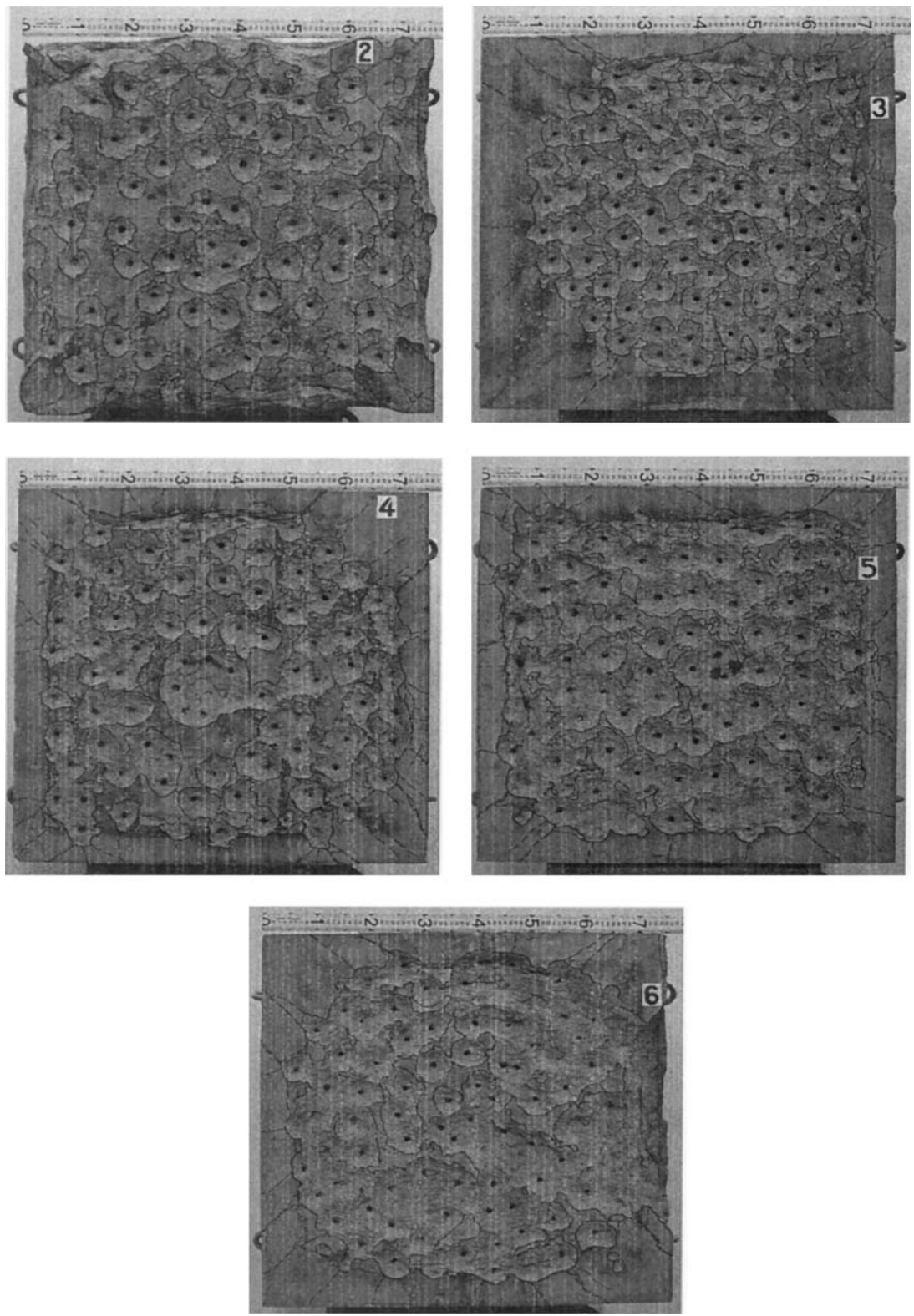

Fig. 2. Top view of concrete blocks two to six after being shot with fragments.

To study the change in material properties, uniaxial compressive and splitting tensile tests were conducted on cylinders drilled from the concrete blocks. However, during drilling, most of the cylinders broke into two pieces. The broken cylinders were measured and drawn, as shown in Fig. 4. For the cylinders drilled from the middle section, the micro-cracks could not be seen from the cross section (compare Fig. 3). Still, the cylinders broke, due to micro-cracking. Cylinders 

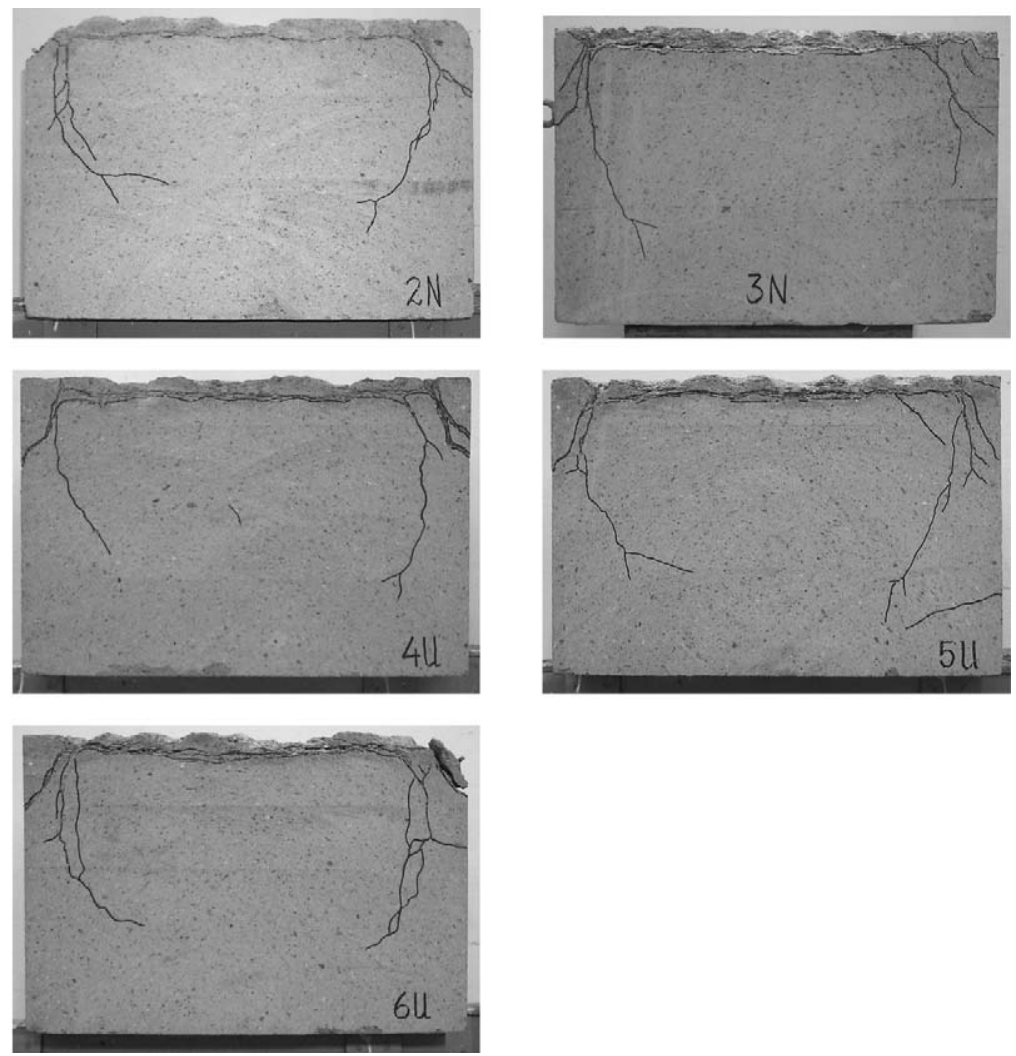

Fig. 3. Macro-crack patterns in the cross section of concrete blocks (after cutting into halves).
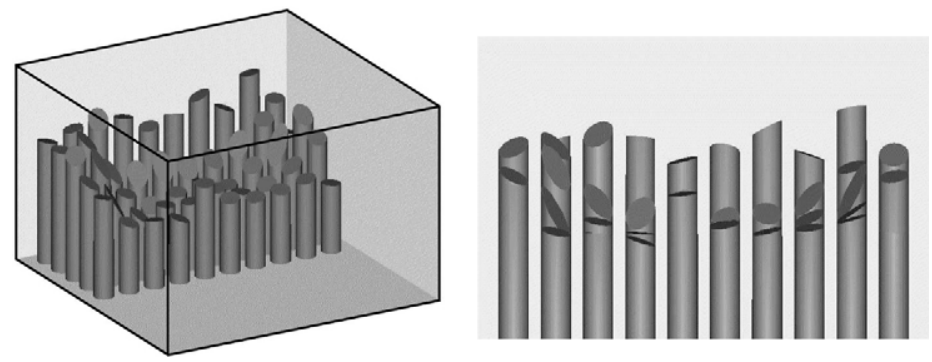

Fig. 4. Crack plane drawn from drilled cylinders.

were also drilled from a reference block that was not subjected to any loading; these cylinders could be drilled out in whole pieces.

\subsection{Uniaxial compressive tests}

From the drilled cylinders, $\phi 50 \times 100 \mathrm{~mm}^{2}$ specimens were sawed out at various heights and smoothed for uniaxial compressive tests. Cylinders were drilled in two directions: horizontally 

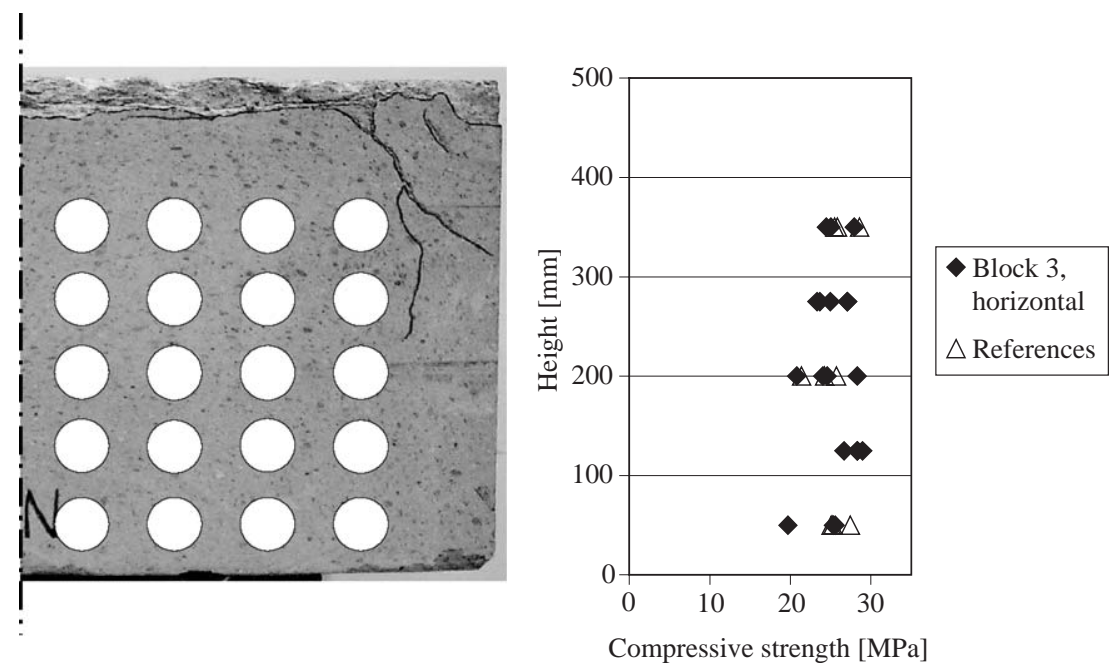

Fig. 5. Uniaxial compressive tests on cylinders drilled horizontally from concrete block three. Marked circles show where the cylinders were drilled.

(perpendicular to the direction of the fragment impacts) and vertically. In concrete block three, the first one analysed, the cylinders were drilled horizontally at heights of 50,125, 200, 275, 350 and $425 \mathrm{~mm}$ measured from the side of the block opposite the surface struck by the fragment. The cylinders drilled at a level of $425 \mathrm{~mm}$ were so severely damaged that none of them could be used for the uniaxial tests. In the uniaxial compressive test on cylinders drilled in the horizontal direction, the strength was hardly affected at all by the fragment impacts, as shown in Fig. 5.

In the vertical direction, $\phi 50 \times 100 \mathrm{~mm}^{2}$ specimen were saved out from the drilled cylinders at heights of 55, 90, 190, 260, 290 and $360 \mathrm{~mm}$, as shown in Fig. 6. The compressive strength was very little affected at a depth of $140 \mathrm{~mm}$ below the fragment impacts. Instead, the uniaxial compressive tests showed somewhat higher strength than in the reference cylinders (concrete block that was not exposed to any loading). However, the specimen that was drilled near the global crack pattern at the block edges had much less strength. For the specimen drilled from the middle section, where micro-cracking occurred, the strength was reduced up to one-third of the uniaxial compressive strength of cylinders drilled from the reference block.

To verify the results of the compressive test on block three, additional specimens were taken from drilled cylinders from blocks four and block six. Three specimens were taken out at various heights, all from the centre of the blocks; the area is marked in Fig. 7, as well as the results from these tests. The overall response was very similar to that of block three. Below the spalling zone, at a depth of $140 \mathrm{~mm}$ below the surface of the fragment impacts, the strength of concrete was slightly higher than in test samples taken from a reference block. At the bottom of the blocks, the strength was less.

\subsection{Uniaxial splitting tensile tests}

From the drilled cylinders specimens were sawed out at various heights and smoothed also for uniaxial splitting tensile tests. For these, the orientation when testing is important, as shown in 

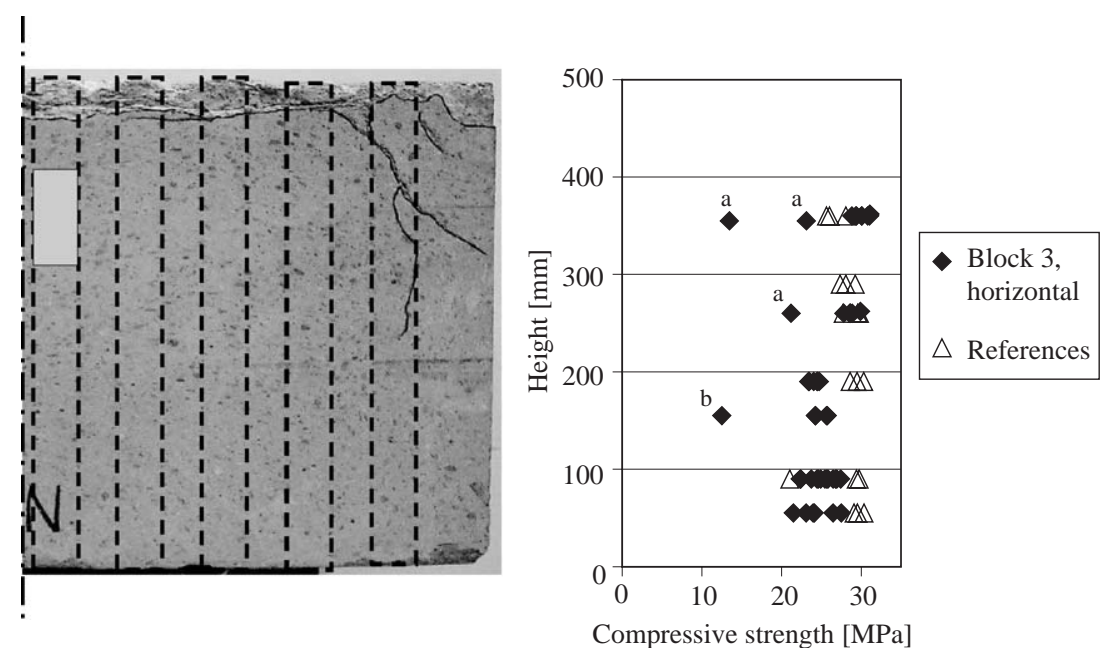

Fig. 6. Uniaxial compressive tests for cylinders drilled vertically in concrete block three. The cylinders are drilled from marked areas. Results at different heights correspond to the centre of gravity for each cylinder. (a) The specimens were taken out near the edge. (b) A crack was visible in the specimen before the test.
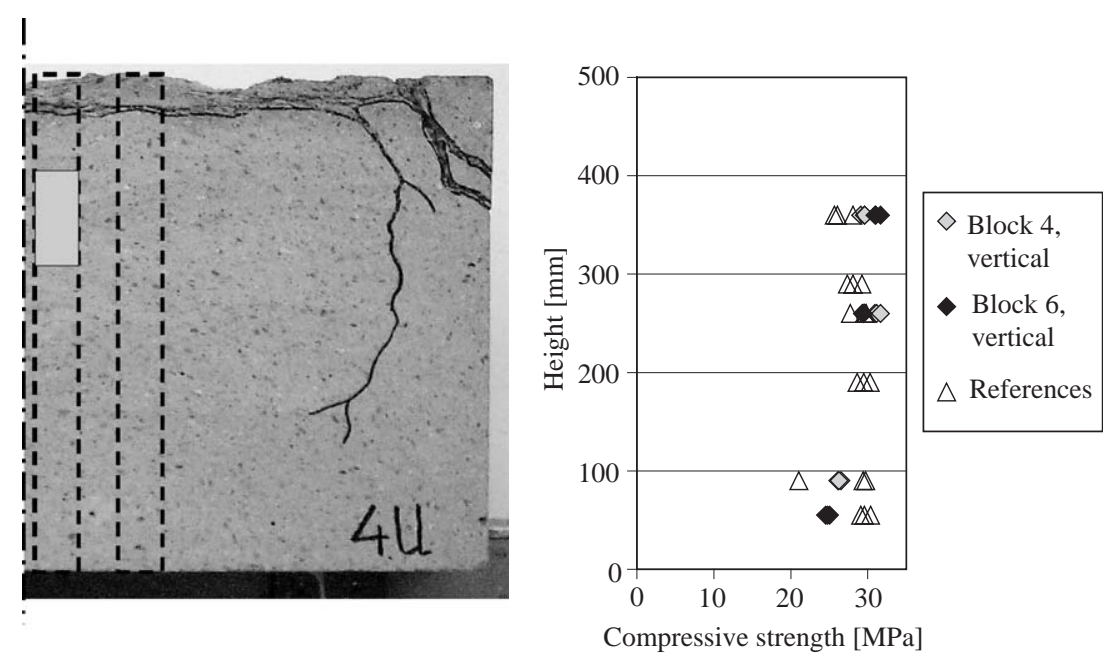

Fig. 7. Uniaxial compressive tests for vertically drilled cylinders: concrete blocks 4 and 6 . The cylinders are drilled from marked areas.

Fig. 8: if a specimen is loaded where there are cracks parallel to the loading, the strength is reduced, but if it is loaded perpendicular to the cracks, the strength is hardly affected. The first concrete block analysed was number three. In the tests, cylinders that were drilled vertically showed very little change in strength, as shown in Fig. 9. This is due to the effect of the crack orientation, as already noted; the main global crack pattern was perpendicular to the direction of the drilling. 


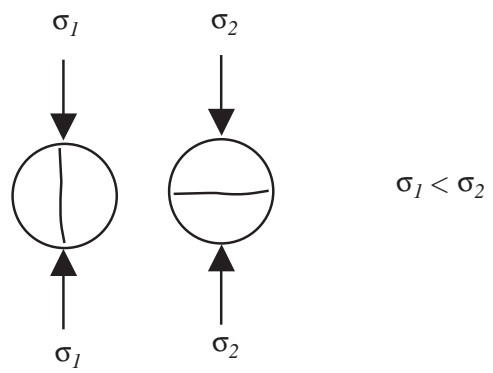

Fig. 8. Influence of the strength due to orientation of a crack.
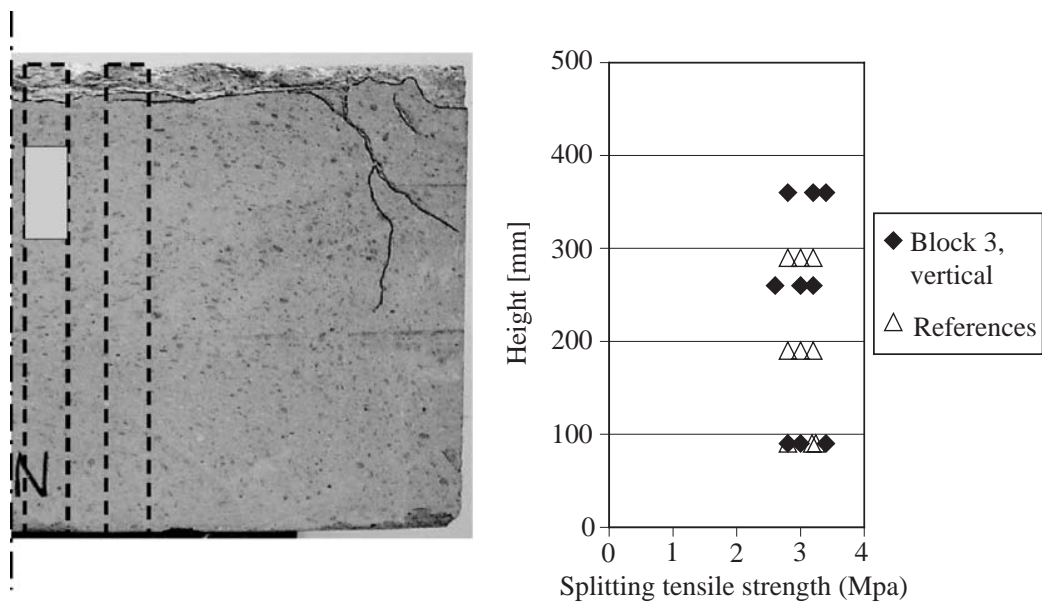

Fig. 9. Uniaxial splitting tensile tests, vertically drilled cylinders, block three.

For horizontally drilled cylinders, as for the compressive tests, the splitting tensile strength was affected very little by the blast wave and fragment impacts at a depth of $150 \mathrm{~mm}$ from the top surface. At the lower levels, where the global crack plane was in the cross section, the strength was reduced in most of the specimens. The results of the splitting tensile tests are shown in Fig. 10. However, for block three, the crack orientation was not registered when the splitting tensile tests were carried out.

To study the effect of the crack orientation in block six, specimens were marked before drilling, so that the main orientation of the micro-cracks was known in the splitting tensile tests. Although the number of tests was limited, some inferences could be made from them. At a level of $50 \mathrm{~mm}$ from the bottom, in the tests with the cracks orientated perpendicular to the loading, the average splitting tensile strength was $2.8 \mathrm{MPa}$. The average strength was $2.5 \mathrm{MPa}$, for the test at the same level, with the cracks orientated parallel to the direction of the loading. The average strength for the references was $2.9 \mathrm{MPa}$. The results are shown in Fig. 11.

Specimens from block four were also tested. For these tests the crack was orientated parallel to the loading. The results were similar to those for block six; the strength was hardly affected in the 

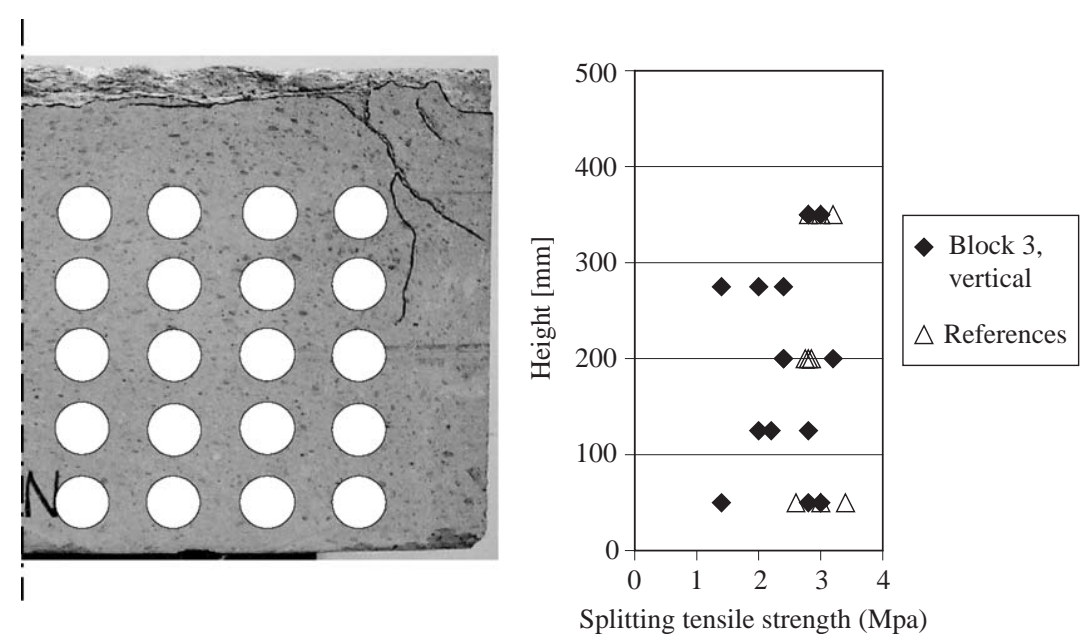

Fig. 10. Uniaxial splitting tensile tests, horizontally drilled cylinders, block three.
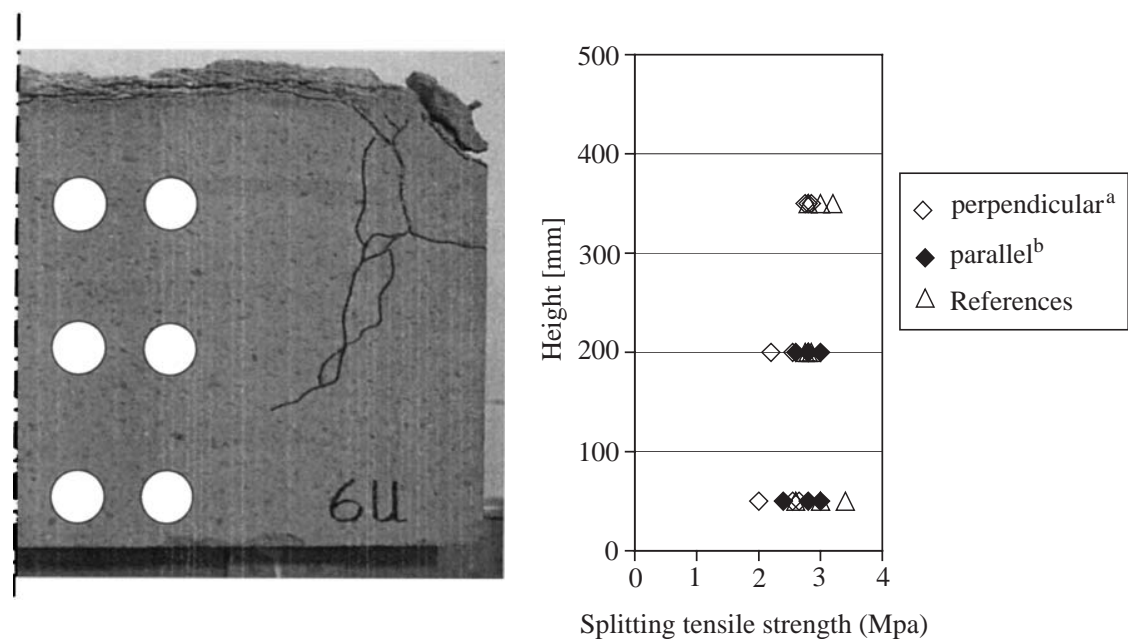

Fig. 11. Uniaxial splitting tensile tests, horizontally drilled cylinders, block six. (a) Crack orientated perpendicular to the direction of the loading. (b) Crack orientated parallel to the direction of the loading.

upper zone (below the fragment impacts), except for one specimen, see Fig. 12. However, for the specimens taken out at the bottom, the strength was lower. At a level $50 \mathrm{~mm}$ above the bottom, the splitting tensile strength was $2.4 \mathrm{MPa}$, which is approximately the same as for block six.

\subsection{Thin-ground sections}

Thin grinding, a precise method to localize the micro-cracking in a material, is commonly used in geological studies, see Kim and McCarter [18]. Here, to study the micro-cracking in the concrete below the impact zone further, a vertically drilled cylinder at the mid section was 

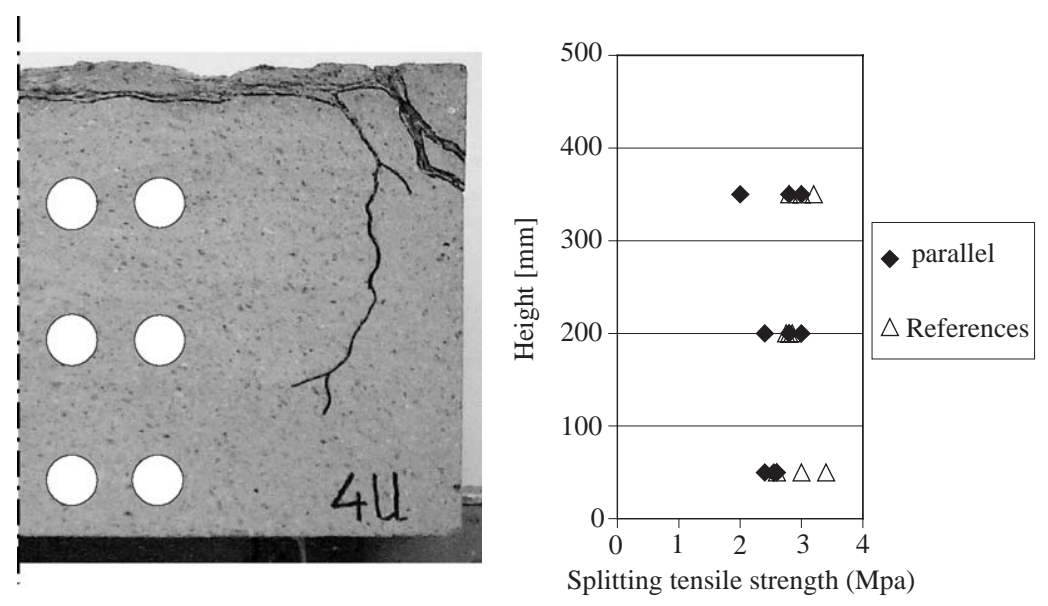

Fig. 12. Uniaxial splitting tensile tests, horizontally drilled cylinders, block four.

thin-ground to a rectangular section of $90 \times 50 \mathrm{~mm}^{2}$, and a thickness of $25 \mu \mathrm{m}$. The section was thin-grounded from two opposite sides from one of the drilled cylinders at a depth between 80 and $170 \mathrm{~mm}$ below the surface of block three. And as a reference, a thin-ground section was also taken from a block that was not subjected to any loading; this section was $90 \times 50 \mathrm{~mm}^{2}$, and had a thickness of $25 \mu \mathrm{m}$. Examples of photographs of the thin-ground sections were taken with a amera (placed inside the microscope), as shown in Fig. 13. To make the micro-cracks easier to see, polarized light was used when the photographs were taken. Also before grinding, the specimens were impregnated with fluorescent penetrant, to make the cracks clearer. The thin-ground sections from the upper zone showed that micro-cracking occurred at a depth of approximately $120 \mathrm{~mm}$ below the surface of the fragment impact. The width of the micro-cracks is up to approximately $0.02 \mathrm{~mm}$. These results verify well the uniaxial tests from drilled cylinders. The concrete strength was not affected at a depth of $150 \mathrm{~mm}$ below the surface. Furthermore, cylinders could not have been drilled $125 \mathrm{~mm}$ below the surface; at this level, there was micro-cracking.

\section{Numerical analyses of the experiments}

\subsection{The numerical model}

A combination of experiments and numerical methods is a powerful tool for detailed analyses. The Lagrangian method has been used in AUTODYN for the analyses. The governing equations in AUTODYN are the Rankine-Hugoniot equations: the conservation of mass, momentum and energy. To complete the description of the continuum, two additional relations describing the material behaviour are needed (besides the load and boundary conditions): first the equation of state (EOS), and second a constitutive model. The EOS relates the pressure to the density; the one used in the numerical analyses was chosen from the AUTODYN material library, since no threeaxial material tests were conducted during the experiments. The constitutive model used was the RHT one in AUTODYN, developed by Riedel [19]. The model, which consists of three yield 


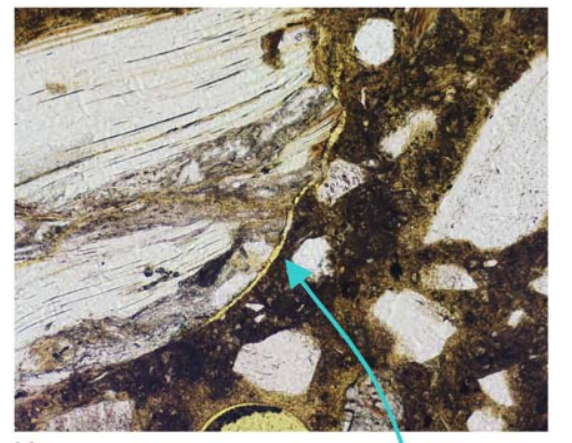

90

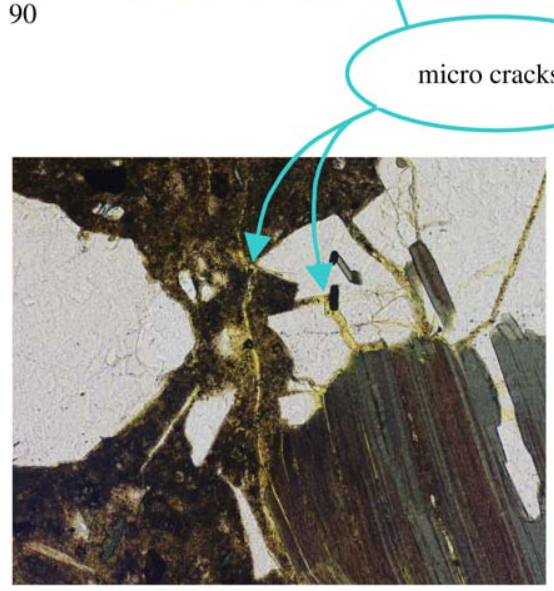

110

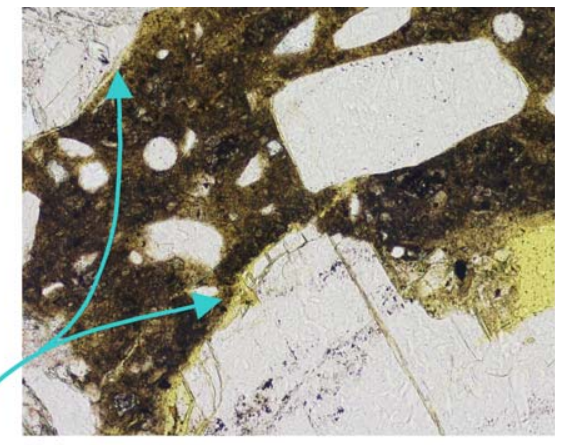

100
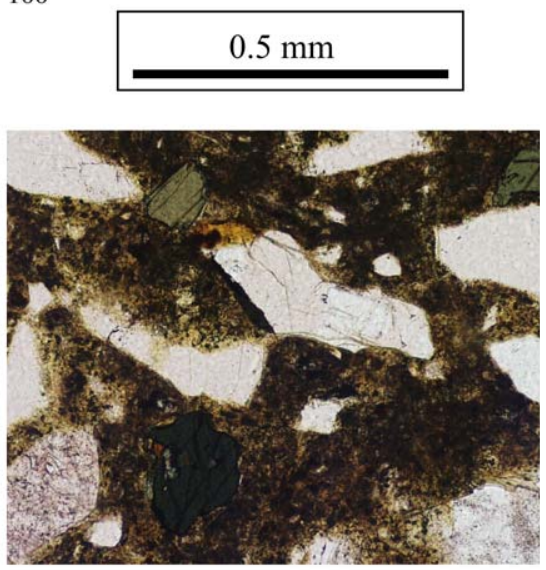

Reference

Fig. 13. Photographs of thin-ground sections at three depths (block 3, and reference). Numbers refer to depth below the surface.

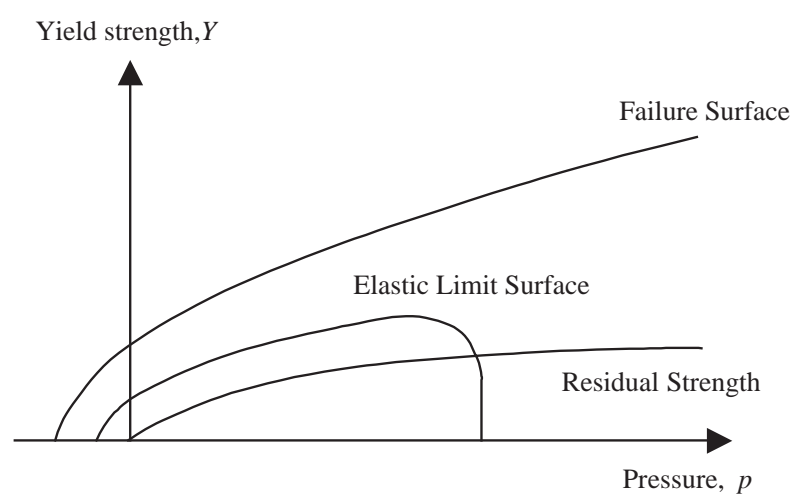

Fig. 14. The RHT constitutive model used for concrete [19].

surfaces, as shown in Fig. 14, includes pressure hardening, strain hardening, strain rate hardening, third-invariant dependence for compressive and tensile meridians, and a damage model for strain softening. For a detailed description of the material model, see AUTODYN [16] and Riedel [19]. 
Table 2

Material parameters for the concrete

\begin{tabular}{ll}
\hline Parameter & Value \\
\hline Young's modulus & $20.7 \mathrm{GPa}$ \\
Compressive cylinder strength & $31.2 \mathrm{MPa}$ \\
Splitting tensile strength & $3.16 \mathrm{MPa}$ \\
Tensile strength & $2.84 \mathrm{MPa}$ \\
Density & $2225 \mathrm{~kg} / \mathrm{m}^{3}$ \\
\hline
\end{tabular}

Several methods to calculate the failure surface have been published, for example, Attard and Setunge [20] and Imran and Pantazopoulou [21]. However, in the analyses presented here, the failure surface and the residual strength are determined by a model proposed in Ref. [20]. The failure surface is determined for confined concrete and static load. To describe the failure surface and the residual strength, the uniaxial compressive cylinder strength and Young's modulus form the input to the model.

The maximum aggregate size used in the concrete mix was $8 \mathrm{~mm}$. From standard uniaxial cylinder tests, the compressive cylinder strength of the concrete was determined; the same was done for the splitting tensile strength. The tensile strength was calculated according to CEB-FIB Model Code 1990 [22]. To determine Young's modulus, another standard test was conducted. All test results and detailed input for the analyses in AUTODYN are published in Leppänen [17]; here the material parameters for concrete are shown in Table 2.

\subsection{The blast wave}

The charge used to shoot the fragments into concrete block three (charge four), was $1.3 \mathrm{~kg}$ hexotol; it was fired from a height of $0.6 \mathrm{~m}$ above the concrete block. In the experiments the pressure was not measured. The pressure-time history from the blast wave was estimated by ConWep [23], see Fig. 15. The arrival time for the blast wave was estimated to be approximately $0.2 \mathrm{~ms}$. However, in the analyses, the pressure was applied to the surface of the concrete block at time zero; this pressure was simplified to a piecewise fall from $25.26 \mathrm{MPa}$ to zero, with a positive duration time of $0.42 \mathrm{~ms}$. Another approximation in the analyses was that the same pressure was applied to the whole surface: in reality, the pressure varies on the surface depending on the distance from the charge and angle.

\subsection{Description of the mesh and boundary conditions}

To analyse penetration in concrete, a very fine mesh must be used, see Refs. [8] or [10]. The usual method is to refine the mesh, and compare the coarse mesh with the refined one until the results differ only negligibly. 2-D analyses were carried out first to determine the mesh size. For the 2-D analyses only one fragment were shot against the concrete block. The same cross section was used in the 2-D analyses as for the 3-D analyses, as shown in Fig. 16. Quadratic elements were used and the number of elements in the plane was varied. Three different mesh sizes were used. The coarse mesh had $50 \times 50$, the medium had $100 \times 100$ and the fine mesh had $200 \times 200$ 


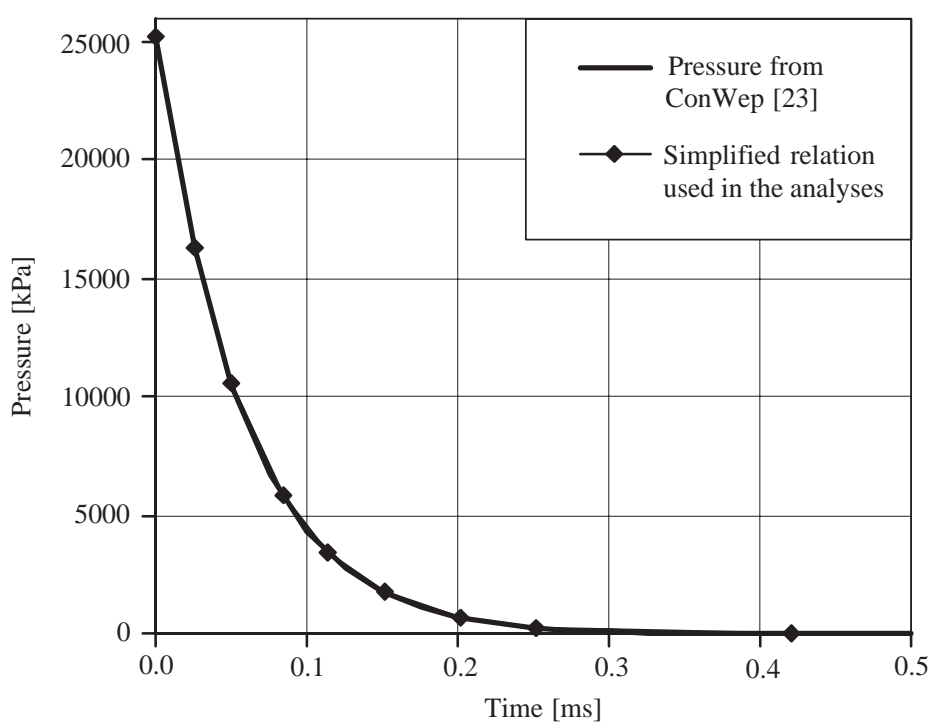

Fig. 15. Pressure-time history from the blast wave; $1.3 \mathrm{~kg}$ hexotol.

Cross section
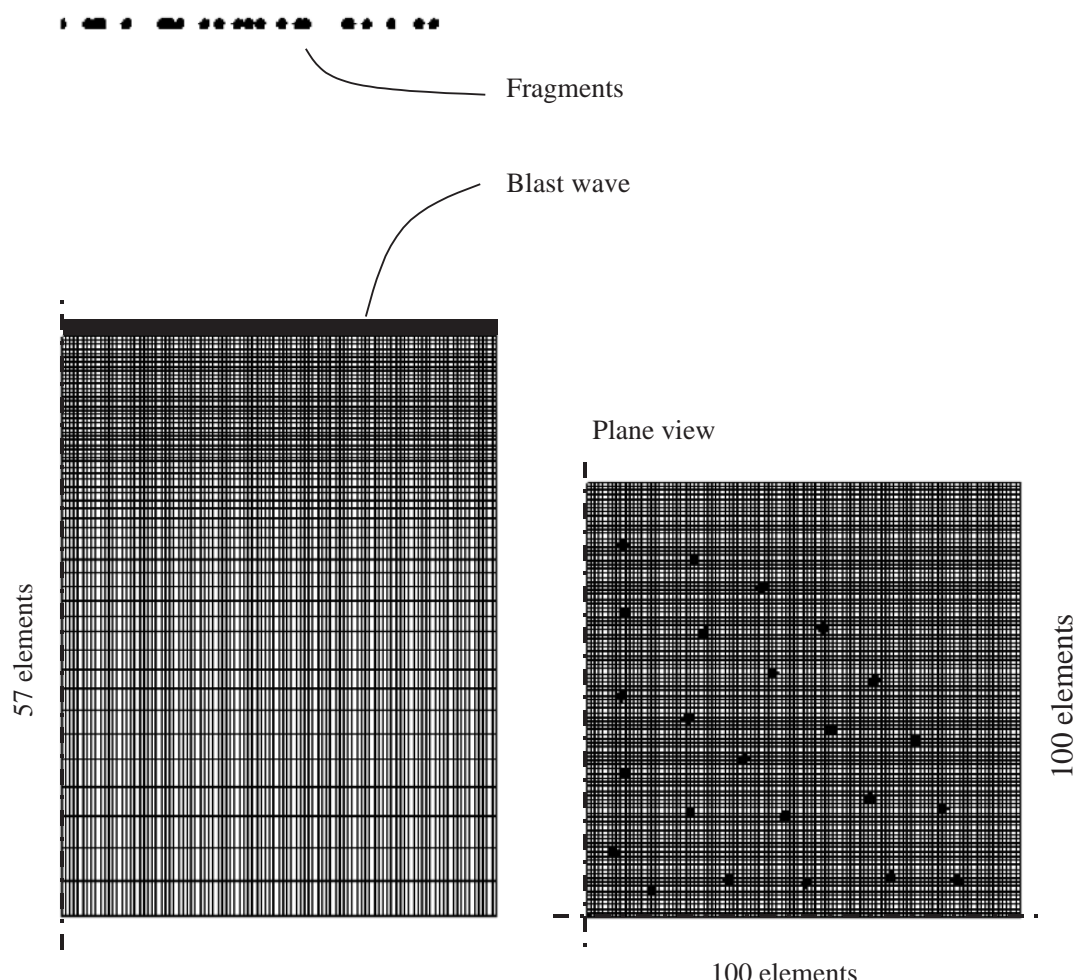

Fig. 16. Numerical mesh. One quarter of the block is modelled. 
elements in the plane. The difference in the spalling between the coarse mesh and the medium mesh was $29 \%$ and the difference was $4 \%$ between the medium mesh and the fine mesh. The medium mesh was chosen for the 3-D analyses. The final 3-D mesh that was used in the analyses is shown in Fig. 16. One quarter of a block (with symmetry boundaries) was modelled; it consisted of $100 \times 100 \times 57$ elements. For the first $100 \mathrm{~mm}$ below the surface of the fragment impacts, 27 fixed size elements were used, and for the $400 \mathrm{~mm}$ below this zone, 30 elements were used. The size of the elements increases, the closer to the bottom they are.

The arrival time for the fragments was calculated as $0.36 \mathrm{~ms}$ (based on an average fragment velocity of $1650 \mathrm{~m} / \mathrm{s}$ and a height of $0.6 \mathrm{~m}$ ). The blast wave hits the concrete block before the fragments do; the difference between the arrival times is approximately $0.16 \mathrm{~ms}$. In the analyses the blast wave was applied at time zero, and the fragments were placed $0.264 \mathrm{~m}$ above the concrete block. This corresponds to a time difference of $0.16 \mathrm{~ms}$, when the fragments strike at a velocity of $1650 \mathrm{~m} / \mathrm{s}$. The location of the fragments in the plane were determined from the experiments, see Fig. 2. The analyses were simplified by designating the angle of impact as $90^{\circ}$. Another simplification was that all of the fragments arrived simultaneously. Furthermore, in the experiment the blocks were placed on a concrete floor, and the stress wave can propagate to it. Whereas in the analyses, at the bottom of the concrete block, both free and fixed boundary conditions in the direction of the loading were used, and in both analyses the energy remains in the block.

\subsection{Results from the numerical analyses}

For concrete block three, three types of analyses were carried out. In the first, only the fragment impacts were taken into account, while in the second and third, both combined blast wave and fragment impacts were analysed, with free and with fixed boundary conditions. In these analyses, the spalling zone was well simulated. A comparison of experiments and an analysis that takes into account only the fragment impacts, viewed from above, is shown in Fig. 17. The results of all of the analyses, first with fragment impacts and then with combined blast wave and fragment impacts, were very similar, viewed from above. However, inside the concrete block below the spalling zone, the blast wave was found to cause more damage in the concrete than in analyses
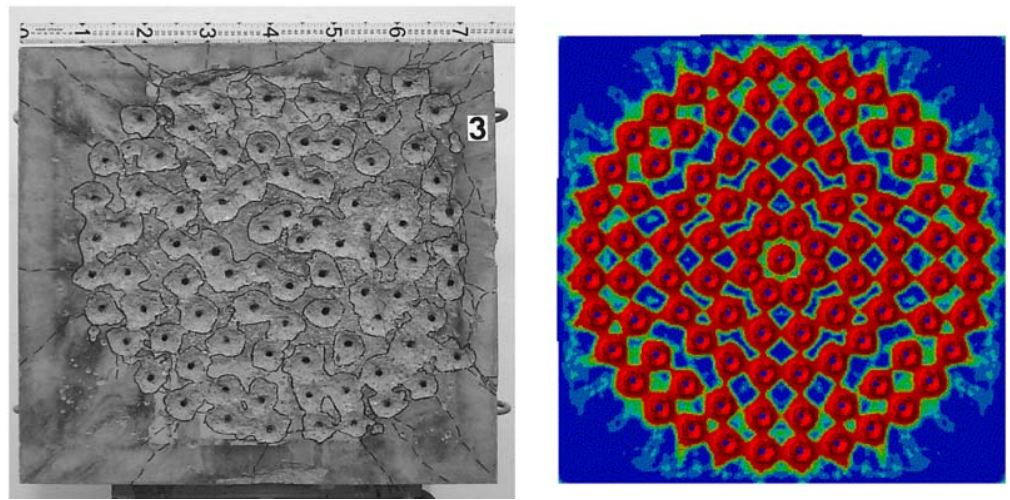

Fig. 17. Comparison of experiments and a contour damage plot from the numerical analysis, as seen from above. 

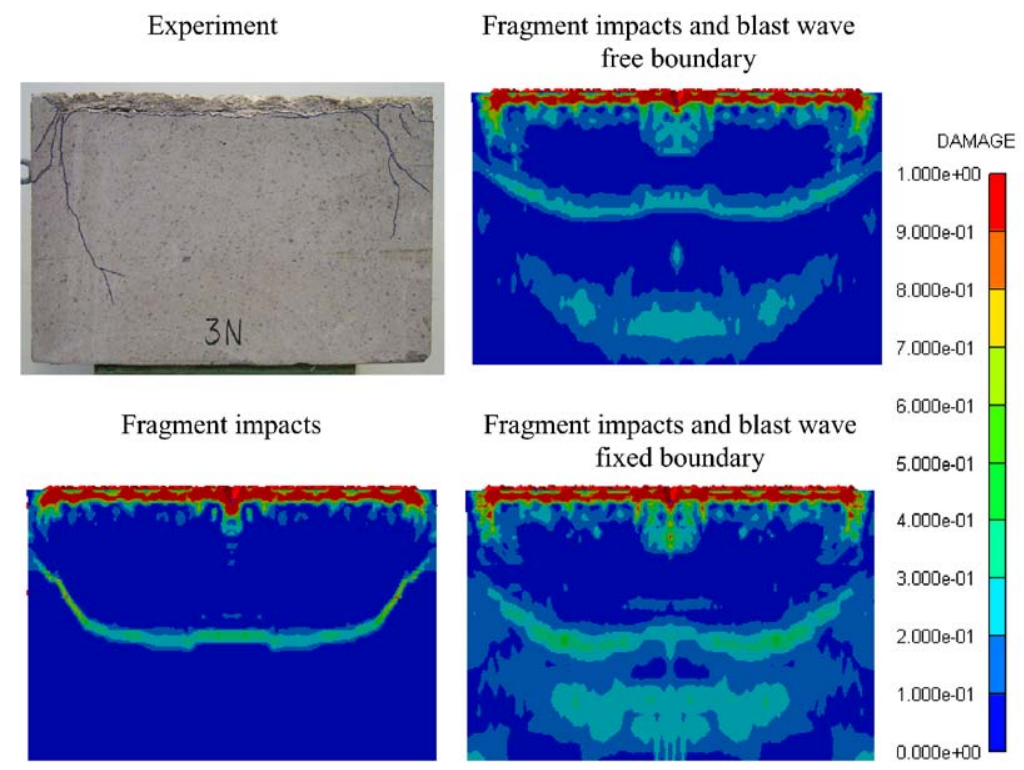

Fig. 18. Comparison of experiments and contour damage plots from the numerical analyses, cross section. The variable damage monitors the cracking strain. Damage is defined to be 0.0 for intact cell and 1.0 for fully failed cell.

where only the fragment impacts where considered. A comparison of experiments and numerical analyses of a cross section, where the fragment impacts alone, and then combined blast wave and fragment impacts, both with free and fixed boundary were studied, see Fig. 18.

For the analyses with the fragment impacts alone, the damage inside the concrete block was localized. When the blast wave was also included in the analyses, the damage zone was larger. There was a minor difference in the damage inside the block by using either free or fixed boundary. When the stress wave propagates, caused by the blast wave, it reflects at the boundaries; if the boundary is free, the stress wave reflects as a tensile wave, and in case of fixed boundary, it reflects as a compressive wave. However, when using fixed boundary, the block is restrained to lift, resulting in tensile stresses at the bottom of the block. Furthermore, when the reflected wave reaches the top surface, energy is consumed to increase the damage that is caused by the fragments that have already struck the surface; this is further discussed in [17]. The damage in the concrete corresponds well with the uniaxial compressive and splitting tensile tests; see results in Fig. 10. At a level $150 \mathrm{~mm}$ below the impact zone, the concrete strength was not affected by the combined blast wave and fragment impacts. At lower levels, the strength was less in the uniaxial tests. The contour damage plots in Fig. 18 show similar behaviour.

\section{Summary and conclusions}

Experiments and numerical analyses presented here show that the damage from a blast wave and fragment impacts is localized at the surface of the impact zone. Thin grinding is an accurate method of finding micro-cracks, and in the experiments here micro-cracking occurred at a depth 
of approximately $120 \mathrm{~mm}$ below the surface struck by the fragments. The concrete strength below this zone, however, was not affected at all. At the boundaries the strength was decreased by reflections of the stress wave.

The uniaxial compressive tests showed some increase in strength below the spalling zone; this is probably due to compaction of the concrete. In the numerical analyses, this zone was undamaged. From the splitting tensile tests, it was also found that the strength was not affected below the spalling zone. Furthermore, it was noted that the orientation when testing the drilled cylinders affected their strength. If a specimen is loaded where the cracks are parallel to the loading, the strength is decreased. The strength of the test specimens that were loaded perpendicular to the cracks was not affected.

In the numerical analyses, the damage in the spalling zone is caused by the fragment impacts. To capture the response of the concrete material behaviour, both fragment impacts and the blast wave must be taken into account. The results from analyses with combined blast wave and fragment impacts showed greater damage inside the concrete block. This indicates that it is possible to distinguish between the global load effects and the local damage effects that are caused by the fragment impacts. Consequently, it may be possible for designers to separate the loads from the blast wave and fragment impacts: the structure could be analysed as a pre-damaged structure with decreased effective depth or width, and the impulse from the fragment impacts could be added to the impulse from the blast wave.

\section{Acknowledgements}

The research presented in this paper was financed by the Swedish Rescue Services Agency. The author would like to thank his supervisor, the Head of the Department of Structural Engineering and Mechanics, Professor Kent Gylltoft, and the reference group members of the project, "Dynamic behaviour of concrete structures subjected to blast and fragment impacts": Björn Ekengren, M.Sc., from the Swedish Rescue Services Agency, Mario Plos, Ph.D., Chalmers University of Technology, and Morgan Johansson, Ph.D., from Reinertsen AB.

\section{References}

[1] Ekengren B. Shelter Regulations, SR - English edition, Swedish Rescue Services Board, Publication B54-168/94, Karlstad, Sweden; 1994. 94pp.

[2] Forsén R, Edin K. Vapenverkan mot flervånings betongbyggnad III: Bestämning av skador från splitterladdningar mot husfasad i skala 1:4 (in Swedish). (Weapon effects on multi-storeyed concrete structures III: Determination of the damage from fragment impacts to façades on a scale of 1:4). FOA report C 20860-2.3, Sundbyberg, Sweden: Swedish Defence Research Agency; 1991. 140pp.

[3] Forsén R, Nordström M. Damage to Reinforced Concrete Slabs Due to the Combination of Blast and Fragment Loading. FOA report B 20101-2.6, Tumba, Sweden: Swedish Defence Research Agency; 1992. 12pp.

[4] Nordström M. Splitterbelastning av betongplattor III: Energiupptagande förmåga hos armerade betongplattor belastade med olika splittertätheter (in Swedish). (Fragment impacts on concrete slabs III: Energy-absorbing ability of reinforced concrete slabs loaded with various fragment impact densities). FOA report 95-0000947(6,2.6) - SE, Stockholm, Sweden: Swedish Defence Research Agency; 1995. 101pp. 
[5] Clegg RA, Sheridan J, Hayhurst CJ, Francis NJ. The application of SPH techniques in AUTODYN-2D to kinetic energy penetrator impacts on multi-layered soil and concrete targets. Eighth International Symposium on Interaction of the Effects of Mutions with Structures, 22-25 April 1997, Virginia, USA.

[6] Johnson GR, Beissel SR. Computed radial stresses in a concrete target penetrated by a steel projectile. Fifth International Conference on Structures Under Shock and Impact V 1998. p. 793-806.

[7] Johnson GR, Stryk RA, Beissel SR, Holmquist TJ. An algorithm to automatically convert distorted finite elements into meshless particles during dynamic deformation. Int J Impact Eng 2002;27(10):997-1013.

[8] Leppänen J. Dynamic Behaviour of Concrete Structures subjected to Blast, Fragment Impacts. Licentiate Thesis, Department of Structural Engineering, Concrete Structures, Göteborg, Sweden: Chalmers University of Technology; 2002. 71pp.

[9] Scheffler DR, Zukas JA. Practical aspects of numerical simulations of dynamic events: material interfaces. Int J Impact Eng 2000;24(8):821-42.

[10] Zukas JA, Scheffler DR. Practical aspects of numerical simulations of dynamic events: effects of meshing. Int J Impact Eng 2000;24(9):925-45.

[11] Johansson M. Structural Behaviour in Concrete Frame Corners of Civil Defence Shelters, Non-linear Finite Element Analyses and Experiments. DoctoralThesis, Department of Structural Engineering, Concrete Structures, Göteborg, Sweden: Chalmers University of Technology; 2000. 204pp.

[12] Krauthammer T. Blast-resistant structural concrete and steel connections. Int J Impact Eng 1999;22(9-10): 887-910.

[13] Krauthammer T, Otani RK. Mesh, gravity and load effects on finite element simulations of blast loaded reinforced concrete structures. Comput Struct 1997;63(6):1113-20.

[14] Ågårdh L, Laine L. 3D FE-simulation of high-velocity fragment perforation of reinforced concrete slabs. Int J Impact Eng 1999;22(9):911-22.

[15] Papados PP. A reinforced concrete structure under impact: response to high rate loads. Sixth International Conference on Structures Under Shock and Impact VI 2000. p. 501-510.

[16] AUTODYN Manuals. Version 4.3, Concord, CA, USA: Century Dynamics, Inc. 2003.

[17] Leppänen J. Splitterbelastad betong, Experiment och numeriska analyser. Fragment impacts into concrete, Experiments and numerical analyses. Department of Structural Engineering and Mechanics, Concrete Structures, report nr. 03:6, Göteborg, Sweden: Chalmers University of Technology; 2003. 74pp [In Swedish].

[18] Kim DS, McCarter MK. Quantitative assessment of extrinsic damage in rock materials. Rock Mech Rock Eng 1998;31(1):43-62.

[19] Riedel W. Beton unter dynamischen Lasten Meso-und makromechanische Modelle und ihre Parameter. Doctoral Thesis, der Bundeswehr Munchen, Freiburg, Germany: Institut Kurzzeitdynamik, Ernst-Mach-Institut; 2000 [in German].

[20] Attard MM, Setunge S. Stress-strain relationship of confined and unconfined concrete. ACI Mater J 1996;93(5):432-42.

[21] Imran I, Pantazopoulou SJ. Plasticity model for concrete under triaxial compression. J Eng Mech-ASCE 2001;127(3):281-90.

[22] CEB-FIB Model Code 1990. Design Code, Lausanne, Switzerland: Thomas Telford; 1993.

[23] ConWep. Collection of conventional weapons effects calculations based on TM 5-855-1, Fundamentals of Protective Design for Conventional Weapons, Vicksburg, USA: US Army Engineer Waterways Experiment Station, 1992. 